\title{
Optimization of pendulum tuned mass damper in tall building under horizontal earthquake excitation
}

\author{
Shahab HASSANI ${ }^{1}$, Majid AMINAFSHAR ${ }^{2}$ \\ ${ }^{1}$ Civil department, Faculty of engineering, Imam Khomeini international university, Qazvin, Iran \\ ${ }^{2}$ Civil department, Faculty of engineering, Imam Khomeini international university, Qazvin, Iran
}

\begin{abstract}
This paper, aims to investigate function of a pendulum tuned mass damper and optimizing of its dynamic parameters in decreasing roof displacement and base forces (shear and moment) of a tall building under a scaled horizontal component of earthquake (the Manjil earthquake on the Qazvin station). Diagrams of relative maximum displacement of roof (maximum roof displacement in building without pendulum to correspond value in building with pendulum), relative maximum base forces (maximum base shear and moment in building without pendulum to correspond values in building with pendulum), and dynamic parameters of pendulum (stiffness and damping coefficient), all in optimum situation, have been plotted. Finally, Maximum displacement of pendulum's mass has been plotted for checking the strike problem and determining the minimum required length of pendulum's span.
\end{abstract}

Keywords: pendulum tuned mass damper, tall building, dynamics of structures, earthquake

\section{Introduction}

Earthquakes have always impressed human's life and have played a fundamental role in almost all the constructions and designs. Unfortunately, this hazardous phenomenon causes a high rate of casualty in people's life and wealth all over the world every year. Although seismology and its methods for reducing damages in structural engineering does not have a long history, theories and devices for controlling earthquake effects have developed saliently during recent decades.

Today, one of the methods for preventing large deformations and damages in buildings is applying dampers. Although dampers are the same when it comes to functionality, they have an extensive variety and are employed in buildings, depending on different structural or geotechnical conditions. A type of damper that has recently attracted a lot of attention for conducting research, is mass damper. This damper, like others, is installed on buildings as an attached supplemental system and it has its specific dynamic parameters (mass, stiffness, and damping). History of using 
Bulletin de la Société Royale des Sciences de Liège, Vol. 85, 2016, p. 514 - 531

mass dampers in structures goes back to Frahm's [1] invention in 1909. His device was an attached mass, elastically connected to the main mass for reducing its vibration. It did not have any damping element for absorbing energy, so it was useful just when its natural frequency was equal or very closed to natural frequency of the main mass. Furthermore, the function of the device was very sensitive to change in frequency of excitation. In 1928, Ormondroyd and Den Hartog [2] developed Frahm's device by adding a damping effect for absorbing energy of vibration. This change decreased the sensitivity of the device to variation of frequency of excitation and also decreased the response in resonance or near resonance situations. Den Hartog also proposed a formula for tuning dynamic parameters of the device.

The next step in developing mass dampers was using a multi-mass system in buildings. Several analyses on the topic were done and published by Welbourn and Bishop [3] in 1952. In the 1960s, this idea - decreasing response of a structure with multi-mass systems - was used in several researches by Harris et al. [4] (1961), and Kaliski et al. [5] (1966). In the recent researches about multi mass dampers, some methods for optimizing these dampers are represented by Shum and Xu [6] (2004), Zuo lei and Nayfeh Samir [7] (2005), Guo and Chen [8] (2007). Between 1975 to 1995, many buildings were constructed all over the world using the vibration absorber devices (Holmes, 1995) [9], some of those were mass dampers and three of these mass dampers were pendulum like (Chifley and Sydney towers in Australia, and P\&G Rokkoisland in japan). For weighted tall buildings, a pendulum attached to the building by a changeable cable (changeable in length), is recommended because of its good efficiency (Sacks and Swallow, 1993) [10]. In such pendulums, natural frequency of pendulum is changeable with changing the length of connecting cable. In the Chifley tower, using this technic, frequency of the pendulum is changed simply by some equipment applied near the pendulum's support (Kwok and Samali, 1995) [11]. Other types of pendulum mass dampers have been studied by Fischer [12] (2007), Sarkar and Gudmestad [13] (2013) in the last recent years.

The present paper, investigates the effect of a pendulum tuned mass damper on a twenty story moment-resist frame (designed by Roeder, 1993) [14]. The frame is modeled and analyzed in OpenSees software with and without pendulum. In process of finding optimum parameters of the pendulum, for each value of $\mu$, the frequency and damping ratio of the pendulum was changed from $0.1 \omega_{1}$ to $3 \omega_{1}$ and from 0 to 0.4 respectively ( $\omega_{1}$ is the first natural frequency of the frame without pendulum and $\mu$ is the ratio of pendulum's mass to frame's effective seismic mass). For 
more simplicity, some of the results became dimensionless. Properly, then, diagrams were plotted. After analyzing process, optimum dimensionless values related to roof displacement, base shear, and base moment, for each value of $\mu$, were derived and plotted with respect to $\mu$. Finally, both diagrams of optimum frequency ratio (ratio of pendulum's frequency to frame's first natural frequency in optimum situation) and optimum damping ratio (ratio of pendulum's damping coefficient to its critical damping in optimum situation) have been plotted and explained, with respect to $\mu$.

\section{Equations of motion in a pendulum with a mobile suspension point}

In writing the equations of motion, it has been supposed that the suspension point of the pendulum can move horizontally and the pendulum oscillates about its static equilibrium point. The forces exerted to pendulum's mass (that act as a point mass) are shown in figure 1. These forces and their values are as below:

$$
\begin{aligned}
q=m g & \text { Gravity Force } \\
F_{n}=m a_{d}=m L \dot{q}^{2} & \text { Centrifugal Force } \\
F_{z}=m a_{s}=m L \ddot{q} & \text { Inertial Force tangent to trajectory of motion } \\
F_{s x}=m \ddot{z}_{x} & \text { Inertial Force due to horizontal movement of pendulum's suspension point } \\
N & \text { Tension }
\end{aligned}
$$

In figure 1 and above relations, $\mathrm{q}$ or $\varphi$ is the angle of pendulum's displacement from the equilibrium point. According to dlambert's principle in $\xi$ and $\zeta$ directions, following equations are derived:

$$
\begin{aligned}
& \sum \xi=0 \rightarrow-F_{t}-F_{g x} \cos q_{(t)}-Q \sin q_{(t)}=0 \\
& \sum \xi=0 \rightarrow-N+F_{n}-F_{s x} \sin q_{(t)}+Q \cos q_{(t)}=0
\end{aligned}
$$


Bulletin de la Société Royale des Sciences de Liège, Vol. 85, 2016, p. 514 - 531

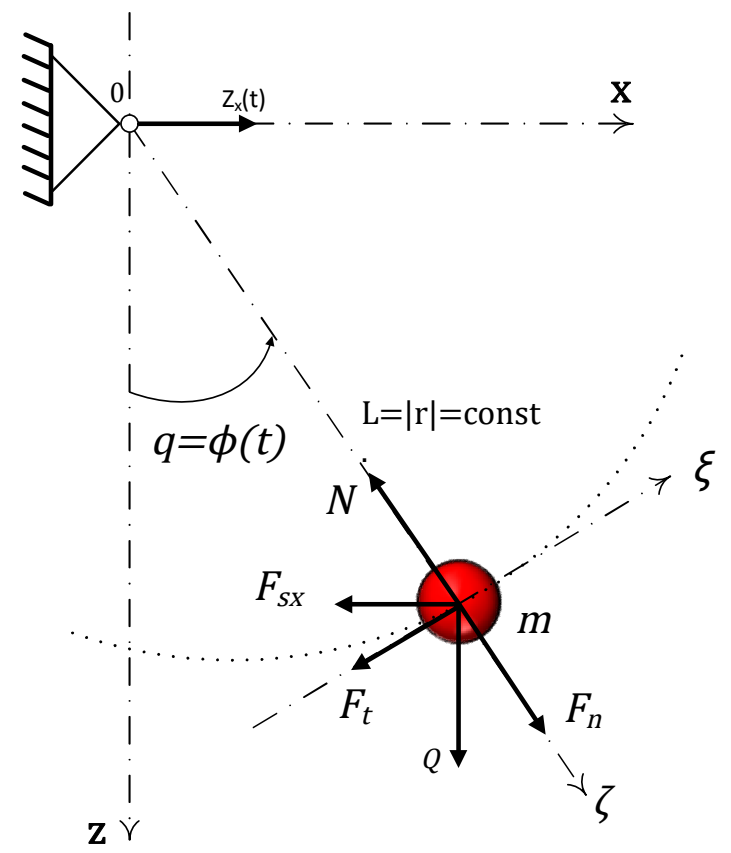

Fig. 1: Forces exerted to pendulum with mobile suspension point

With replacing the values of forces in relations 1 and 2, the following equation is derived:

$$
\ddot{q}_{(t)}+\frac{g}{L} \sin q_{(t)}+\frac{\ddot{z}_{x_{(t)}}}{L} \cos q_{(t)}=0
$$

Equation (3) is a nonlinear differential equation that describes the vibration of a pendulum with mobile suspension point. When the displacement of the pendulum is small, this equation with removing the higher order differential components is written as below:

$$
m \ddot{q}_{(t)}+\frac{m g}{L} q_{(t)}=-\frac{m \ddot{z}_{x_{(t)}}}{L}
$$




\section{Verification and characteristics of the model}

In this paper, a moment-resist frame with three spans and twenty stories (as shown in figure 2) has been modeled with OpenSees. Sections of the columns and beams are presented in tables 1 and 2 respectively.

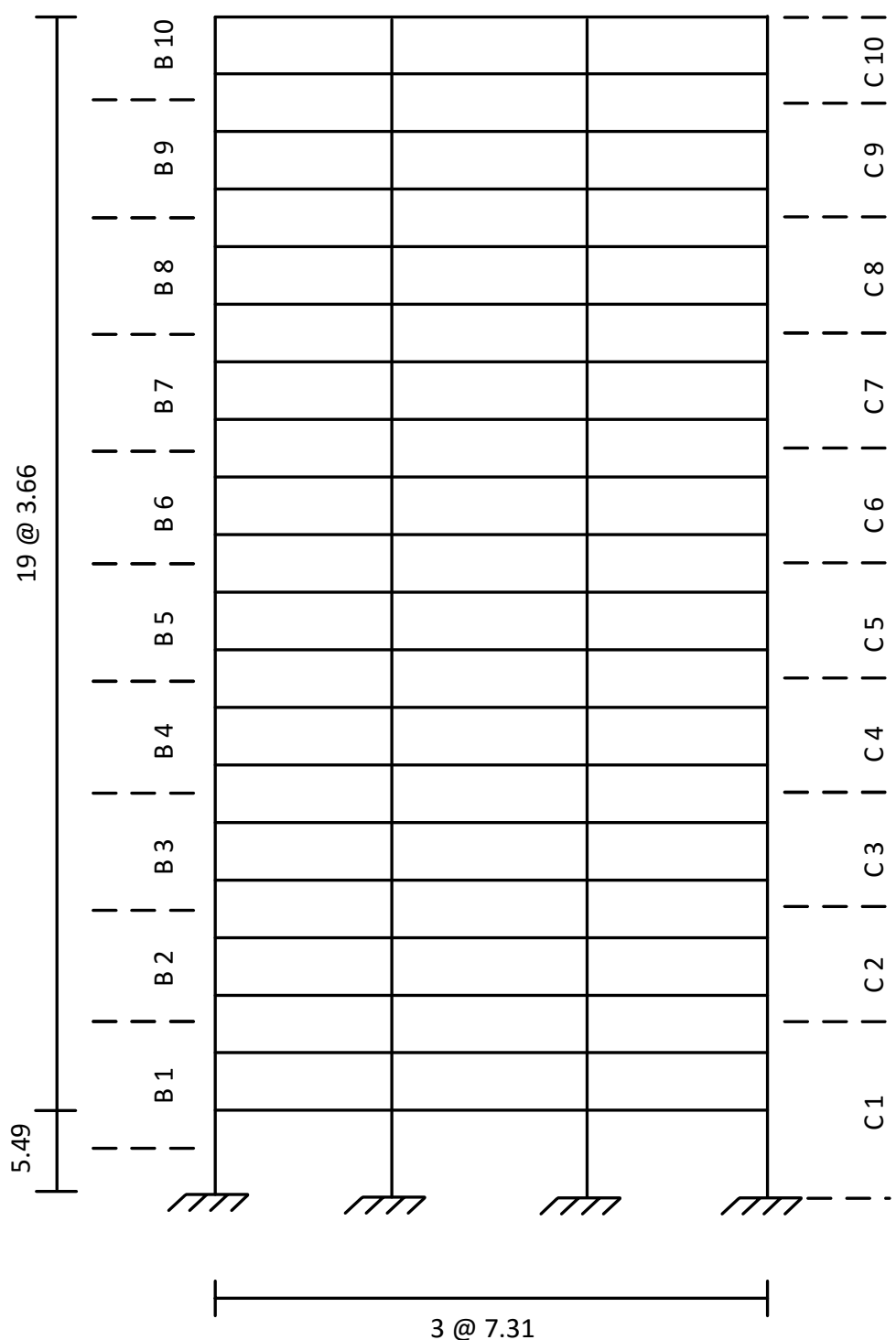

Fig. 2: Moment - resist frame modeled in OpenSees 
Bulletin de la Société Royale des Sciences de Liège, Vol. 85, 2016, p. 514 - 531

Table 1: Column sections in twenty story frame

\begin{tabular}{|c|c|c|}
\hline & Outer Columns & Interior Columns \\
\hline $\mathrm{C} 1$ & W 14x211 & W 36x230 \\
\hline $\mathrm{C} 2$ & W 14x193 & W 36x 182 \\
\hline $\mathrm{C} 3$ & W $14 \times 178$ & W 36x 170 \\
\hline $\mathrm{C} 4$ & W 14x159 & W 36x 160 \\
\hline $\mathrm{C} 5$ & W $14 \times 145$ & W 36x 150 \\
\hline C6 & W 14x132 & W 36x135 \\
\hline $\mathrm{C} 7$ & W $14 \times 120$ & W 30x132 \\
\hline $\mathrm{C} 8$ & W 14x109 & W 30x116 \\
\hline C9 & W 14x90 & W 27x 102 \\
\hline $\mathrm{C} 10$ & W $14 \times 74$ & W 27x84 \\
\hline
\end{tabular}

Table 2: Beam sections in twenty story frame

\begin{tabular}{|c|c|}
\hline & Beams \\
\hline B1 & W 27x102 \\
\hline B2 & W 27x102 \\
\hline B3 & W 27x94 \\
\hline B4 & W 27x94 \\
\hline B5 & W 27x84 \\
\hline B6 & W 27x84 \\
\hline B7 & W $24 \times 76$ \\
\hline B8 & W 24x76 \\
\hline B9 & W 24x68 \\
\hline B10 & W 24x62 \\
\hline
\end{tabular}


All the geometric and loading characteristics of the frame are similar to Roeder's building. Values of dead and live loads in his paper on roof and stories, are as follow:

$$
\begin{aligned}
& \text { D.L. }=17500 \mathrm{~N} / \mathrm{m} \\
& L_{.} L_{\text {IStories }}=8750^{\mathrm{N}} / \mathrm{m} \\
& L_{x} L_{\text {Roof }}=4375^{\mathrm{N}} / \mathrm{m}
\end{aligned}
$$

The height of the first and other stories are $5.49 \mathrm{~m}$ and $3.66_{\mathrm{m}}$ respectively. Length of the spans are equal and for each one is $7.31_{m}$. Considering twenty percent of the live load and hundred percent of the dead load as components of the frame's total effective seismic mass, this value was calculated to be around 860 ton

The suspension point of the pendulum was modeled at the twentieth story in the middle of the frame's width. The mass of the pendulum was also connected to the suspension point by a rigid link with the length of $3.66_{m}$ (equal to length of a story). Elements used for modeling the beams and columns in OpenSees are all in type of Elastic Beam Column. It should be noted that, this type of element, does not consider shear deformations. For verifying the model, the frame was also modeled in ETABS (without considering shear deformations) and values of its first twelve periods was taken from software's outputs. These twelve periods that are the same with their correspond values in OpenSees, are presented in table 3.

To define the frame's inherent damping, Rayleigh damping command was used in OpenSees considering the number of mode, in which the cumulative modal contribution was more than $90 \%$ [15] (eight modes in this frame).

\section{Response of the frame under the earthquake excitation}

To excite the frame, horizontal acceleration of the Manjil earthquake on the Qazvin station (the one with bigger P.G.A.) was selected. This acceleration was scaled according to the Iranian code of practice for seismic resistant design of buildings and exerted to the frame. As described previously, for more simplicity in representing the results, some dimensionless parameters are defined as below: 
- $\mu$ (mass ratio, ratio of the pendulum's mass to the frame's effective seismic mass)

- $f_{r}$ (frequency ratio, ratio of the pendulum's frequency to the first natural frequency of the frame without pendulum)

- Relative maximum displacement of roof (ratio of the maximum displacement of roof in the pendulum-frame system to correspond value in the frame without pendulum)

- Relative maximum base shear (ratio of the maximum base shear in the pendulum-frame system to correspond value in the frame without pendulum)

- Relative maximum base moment (ratio of the maximum base moment in the pendulumframe system to correspond value in the frame without pendulum)

- $\xi_{\mathrm{p}}$ (damping ratio, ratio of the pendulum's damping coefficient to its critical damping)

Table 3: Periods of the first twelve modes of twenty story frame in ETABS and OpenSees

\begin{tabular}{cc}
\hline ETABS & OpenSees \\
\hline 2.088 & 2.088 \\
\hline 0.735 & 0.735 \\
\hline 0.419 & 0.419 \\
\hline 0.293 & 0.293 \\
\hline 0.220 & 0.220 \\
\hline 0.173 & 0.173 \\
\hline 0.140 & 0.140 \\
\hline 0.116 & 0.116 \\
\hline 0.098 & 0.098 \\
\hline 0.085 & 0.085 \\
\hline 0.073 & 0.073 \\
\hline 0.065 & 0.065 \\
\hline
\end{tabular}

In analyzing process, mass ratio was changed from 0.01 to 0.2 , and for each value in this domain, with regard to variation bounds for the damping ratio $(0<\xi<0.4)$ and the frequency ratio $\left(0.1 \omega_{1}\right.$ $\left.<f_{r}<3 \omega_{1}\right), 945$ analyses were done with OpenSees. In the next step, the derived faces related to 
the roof displacement, base shear, base moment, and maximum displacement of the pendulum's mass were plotted, all respect to the damping ratio and frequency ratio. These faces have been shown in figures 3 to 6 for $\mu=0.05$.

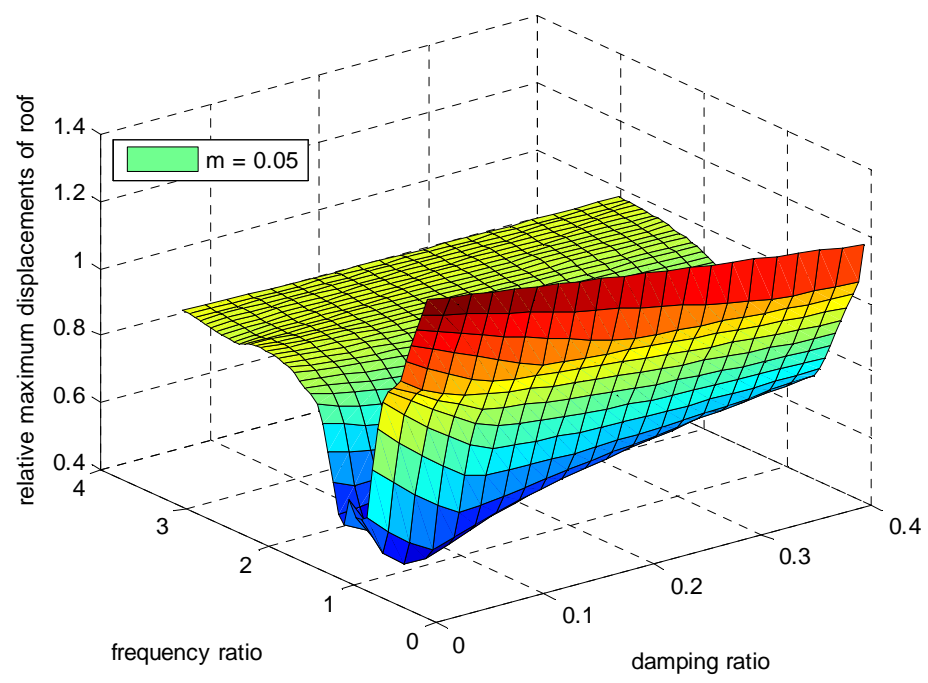

Fig. 3: Relative maximum displacements of roof for $\mu=0.05$

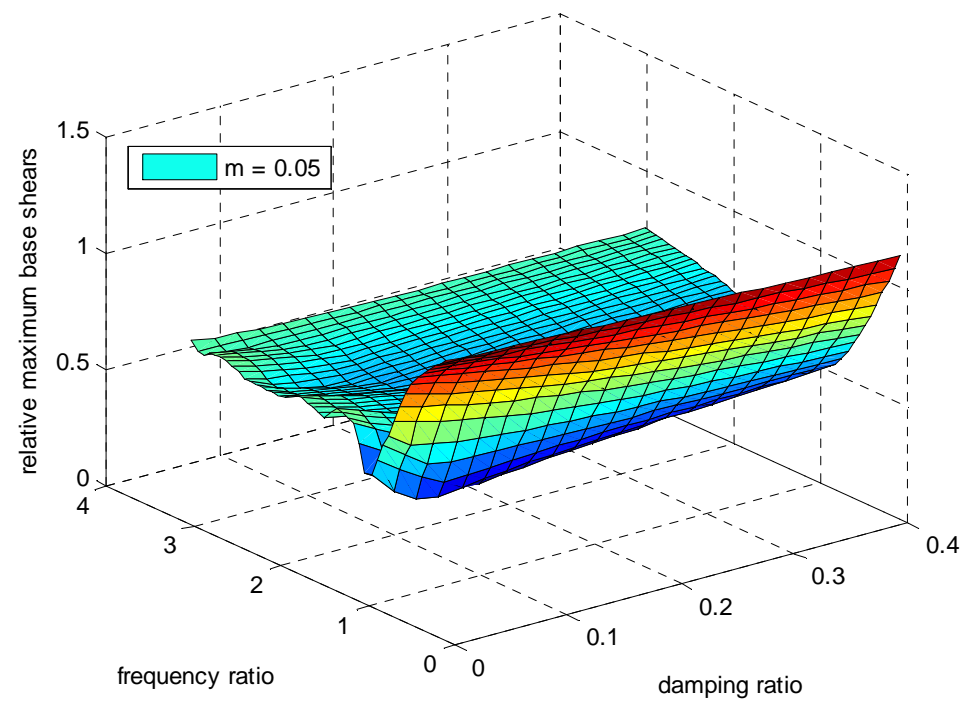

Fig. 4: Relative maximum base shears for $\mu=0.05$ 


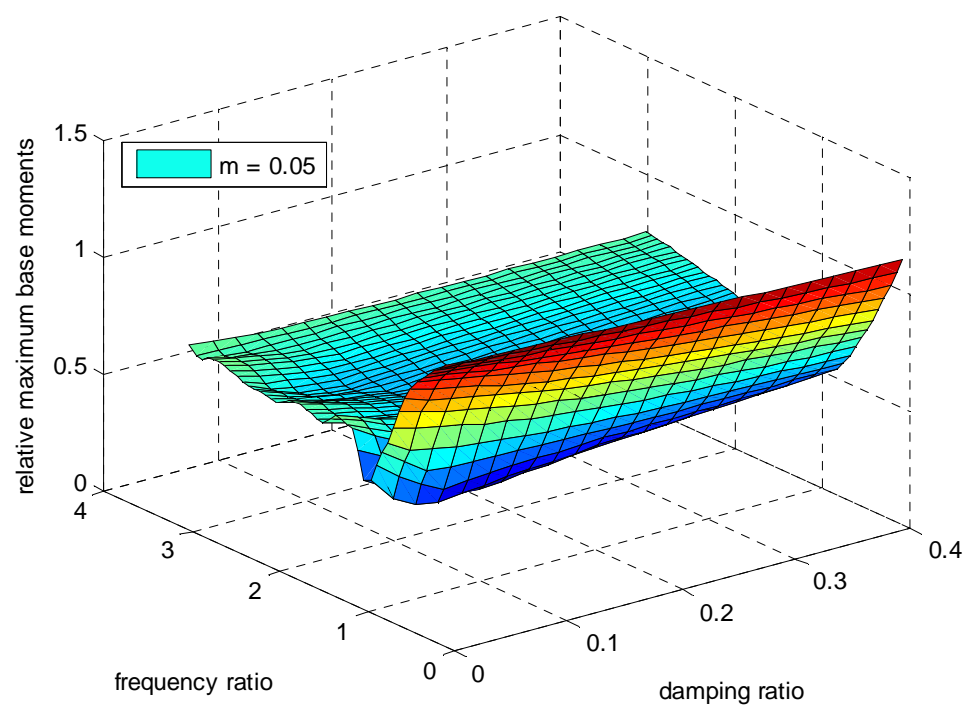

Fig. 5: Relative maximum base moments for $\mu=0.05$

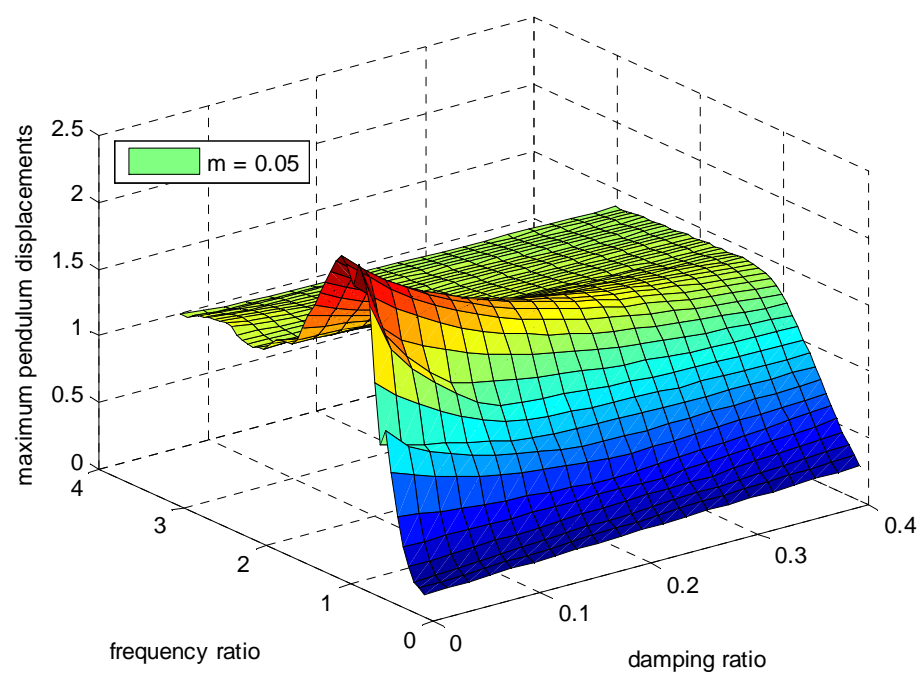

Fig. 6: Maximum displacements of pendulum's mass (meter) for $\mu=0.05$

Minimum values of the faces related to the roof displacement, base shear, base moment and also values of the damping ratio and frequency ratio corresponding to these minimums were derived and used to plot the diagrams related to the roof displacement, base shear, and base moment (all 
Bulletin de la Société Royale des Sciences de Liège, Vol. 85, 2016, p. 514 - 531

in optimum situation and with respect to the mass ratio). These diagrams are shown in figures 7 to 10 .

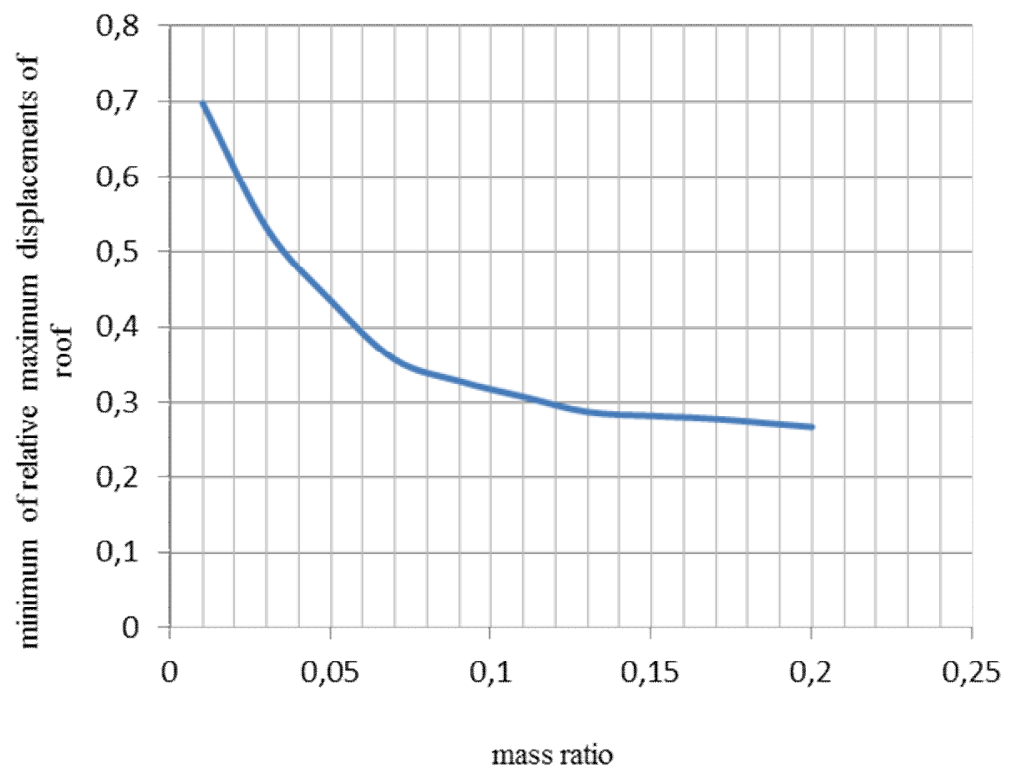

Fig. 7: Minimum of relative maximum roof displacements (optimum situation)

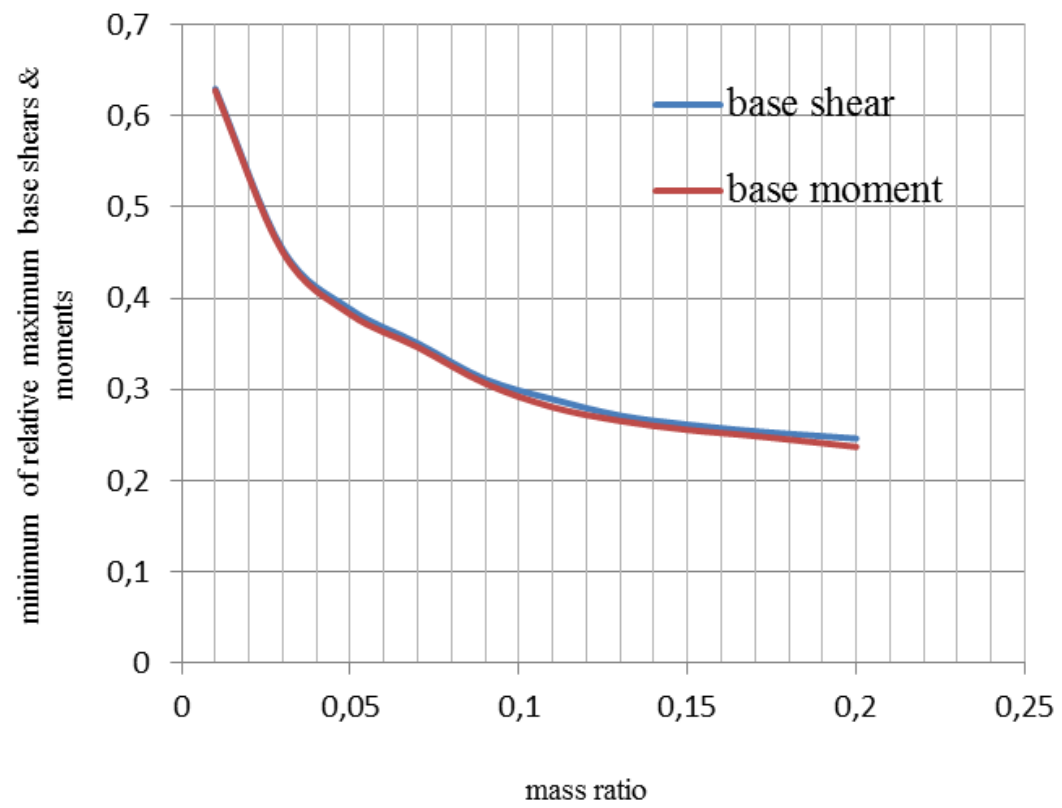

Fig. 8: Minimum of relative maximum base shears and moments (optimum situation) 
Bulletin de la Société Royale des Sciences de Liège, Vol. 85, 2016, p. 514 - 531

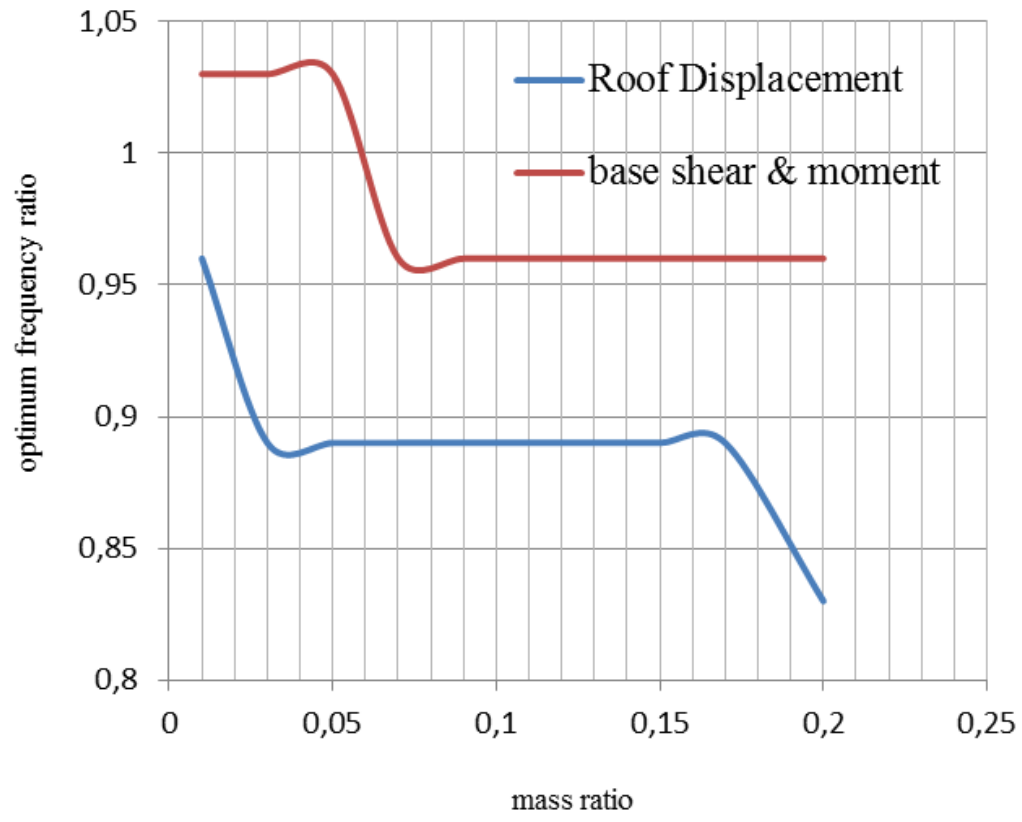

Fig. 9: Optimum frequency ratio related to roof displacement, base shear, and base moment

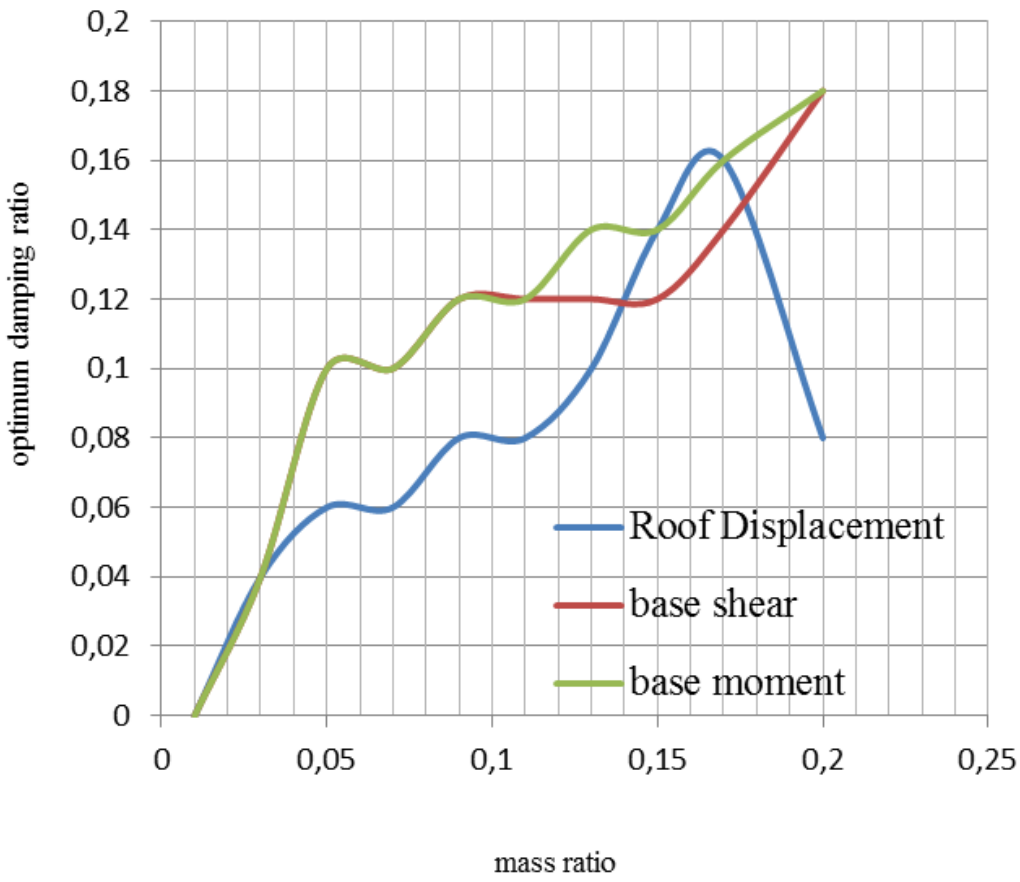

Fig. 10: Optimum damping ratio related to roof displacement, base shear, and base moment 
Figures 7 and 8 show that the ratios related to roof displacement, base shear, and base moment, all decrease with increasing $\mu$. In both figures, the slope of the curves in the first part of diagrams (from $\mu=0.01$ to almost $\mu=0.1$ ) is significantly greater than the second part (from $\mu=$ 0.1 to $\mu=0.2$ ). considering this fact and other negative side effects caused by selecting a large mass for pendulum, a mass ratio between 0.01 to $0.1(0.01<\mu<0.1)$ is recommended. In this domain of $\mu$, main efficiency of pendulum in decreasing roof displacement, base shear, and base moment is reachable and these indices are decreased up to $70 \%$ than their correspond values in the frame without pendulum. The time histories of the indices in the frame with and without the pendulum are shown in figures 11 to 13 . These figures show the difference between values of time histories in the frame, and correspond values in the frame-tuned pendulum system with $\mu=$ 0.1 .

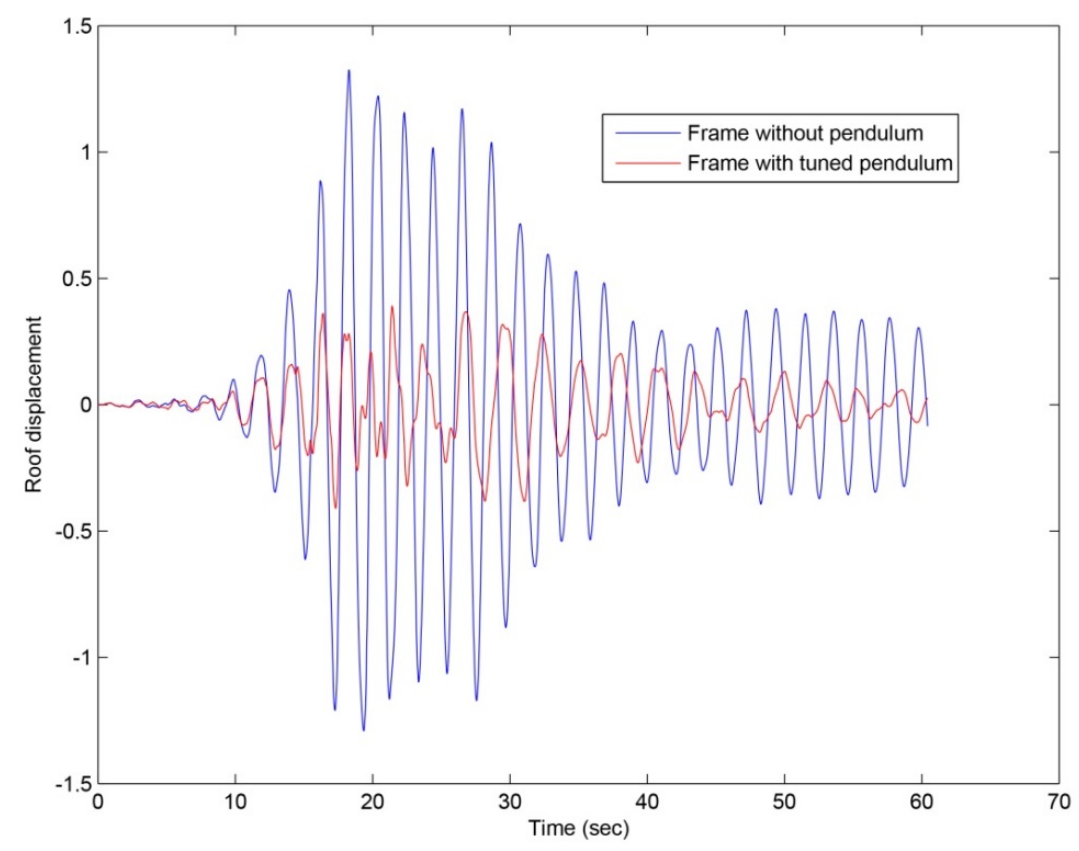

Fig. 11: Time histories of roof displacement (meter) in frame with and without pendulum $(\mu=0.1)$ 
Bulletin de la Société Royale des Sciences de Liège, Vol. 85, 2016, p. 514 - 531

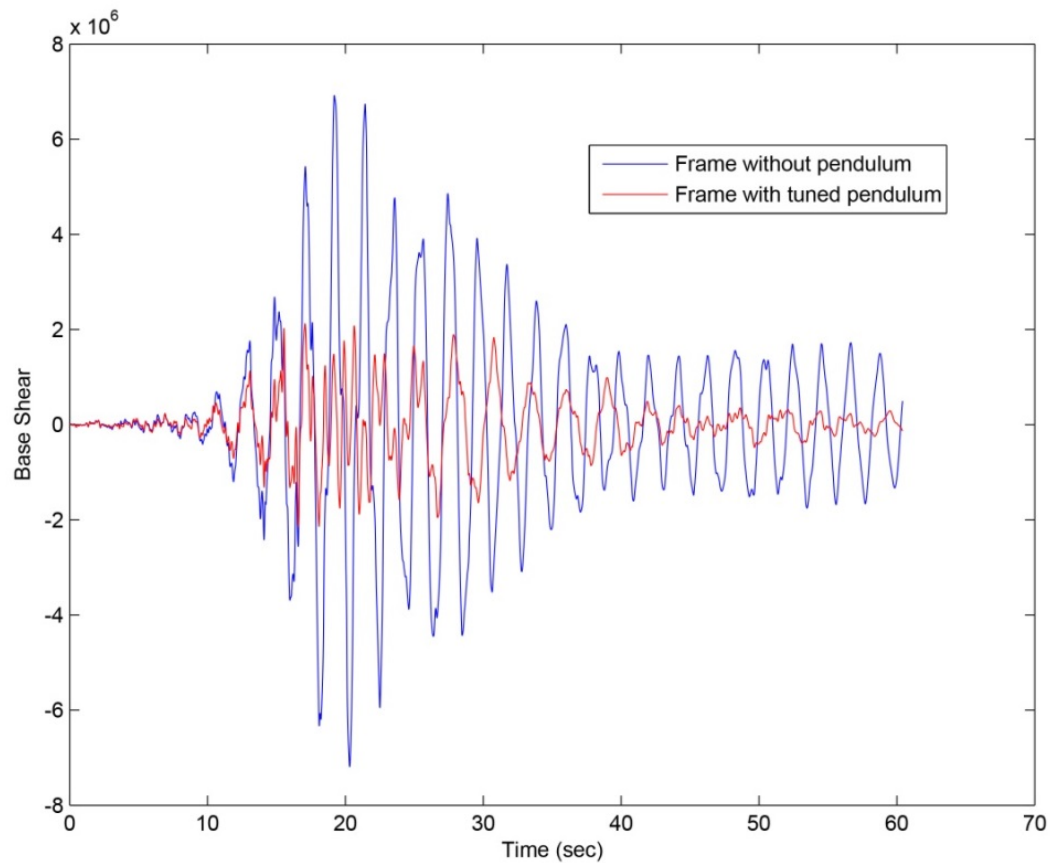

Fig. 12: Time histories of base shear (newton) in frame with and without pendulum $(\mu=0.1)$

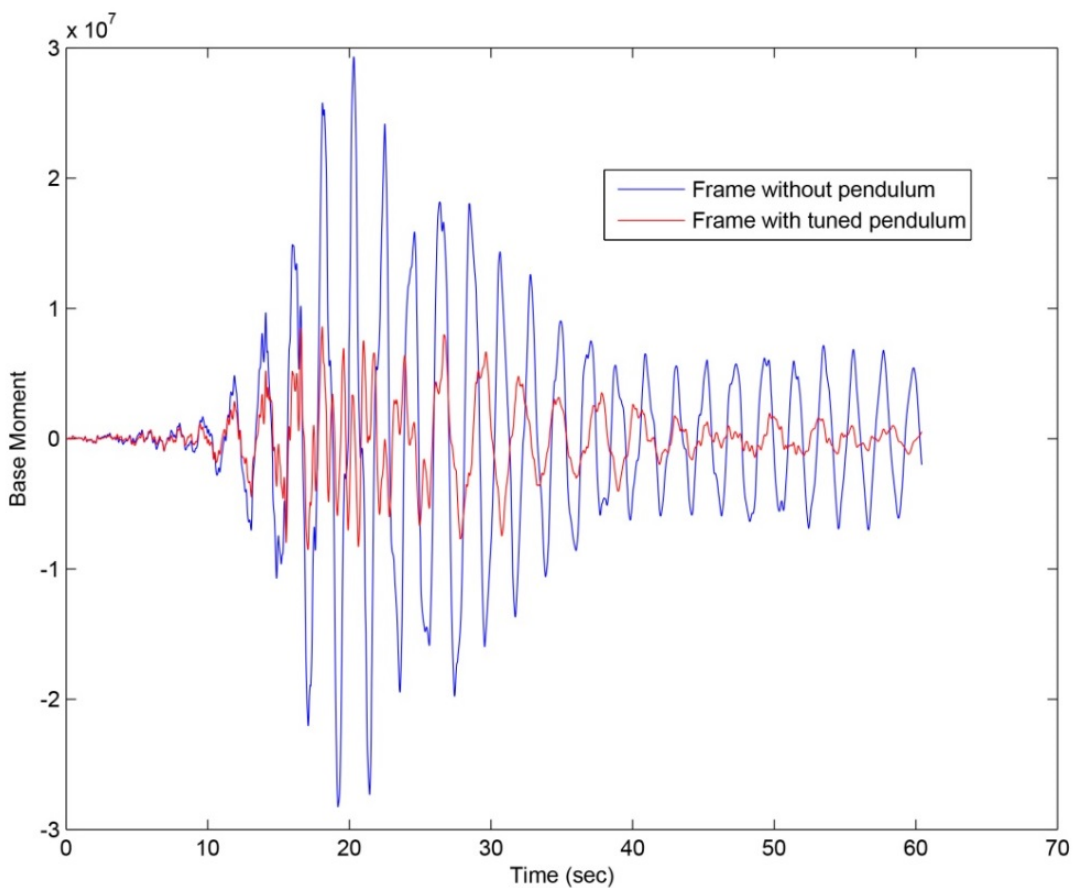

Fig. 13: Time histories of base moment (newton-meter) in frame with and without pendulum $(\mu=0.1)$ 
Bulletin de la Société Royale des Sciences de Liège, Vol. 85, 2016, p. 514 - 531

Figure 9 shows the values of optimum frequency ratio related to roof displacement, base shear, and base moment. In both curves of figure 9, the optimum frequency ratio is a decreasing function, and decreases or stays fixed (in some parts) with increasing $\mu$. The range of optimum frequency ratio is between 0.83 to $0.96\left(0.83<f_{r}<0.96\right)$ for optimizing roof displacement and 0.96 to $1.03\left(0.96<f_{r}<1.03\right)$ for optimizing base shear and moment.

Figure 10 shows the optimum damping ratio related to roof displacement, base shear and base moment. It is seen that, the optimum damping ratio is an increasing function in all curves of the figure, and increases or stays fixed (in some parts) with increasing $\mu$ (except the ending part of the curve related to roof displacement). The optimum damping ratio have values between 0 to $0.18\left(0<\xi_{p}<0.18\right)$ for all three mentioned indices.

Finally, with deriving the optimum values of damping ratio and frequency ratio for each $\mu$, and with note to the face of pendulum's maximum displacements, diagrams of pendulum's maximum displacement in optimum situation (for all three mentioned indices) have been plotted in figure 14. These diagrams are used for checking the strike of pendulum's mass to frame, and also for determining minimum required length of pendulum's span.

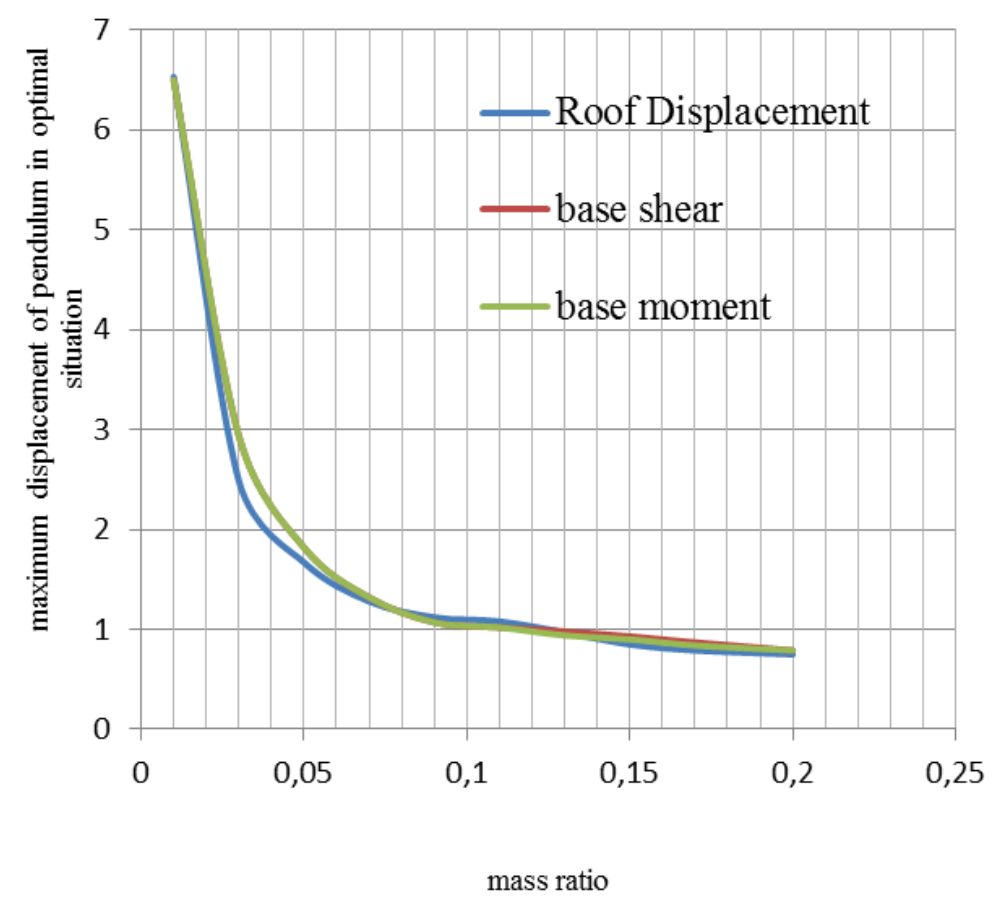

Fig. 14: Pendulum's maximum displacement in optimum situation for all three indices 
Bulletin de la Société Royale des Sciences de Liège, Vol. 85, 2016, p. 514 - 531

The curves in figure 14 also have a greater slope in their first parts (from $\mu=0.01$ to almost $\mu=0.04$ ) rather than second parts (from $\mu=0.04$ to $\mu=0.2$ ). considering this fact, the desirable mass ratio that was offered between 0.01 to 0.1 before, is now recommended to be limited between 0.04 to $0.1(0.04<\mu<0.1)$. Also, regarding figure 14 and dimensions of the frame (length of spans is $7.31_{m}$ ), after $\mu=0.03$, there is no concern about the striking of the pendulum's mass and frame.

\section{Conclusions}

In this paper, a moment-resist frame with twenty stories, three spans, and a pendulum tuned mass damper attached to the twentieth story was modeled in Opensees. A scaled acceleration (the Manjil earthquake on the Qazvin station) was exerted to the frame as an excitation. A number of analyses were done with changing the dynamic parameters of the pendulum (mass, frequency, and damping coefficient), and faces related to roof displacement, base shear, and base moment were plotted. Minimum points of these faces was derived and plotted in optimum correspond diagrams. Analyzing these diagrams yields conclusions listed as below:

1) considering the low slope value in the second part of the curve related to roof displacement (figure 7), and the high slope value in the first part of curves representing maximum displacement of pendulum in optimum situation (figure 14), the desirable range for selecting mass ratio is recommended to be between 0.04 to $0.1(0.04<\mu<0.1)$. In this domain of $\mu$, in the pendulumframe system, the maximum displacement of roof, maximum base shear, and maximum base moment all are reduced up to $70 \%$ rather than correspond values in the frame without pendulum (see figures 11-13).

2) optimum frequency ratios are between 0.83 to $0.96\left(0.83<f_{r}<0.96\right)$ for roof displacement index and between 0.96 to $1.03\left(0.96<f_{r}<1.03\right)$ for base shear and moment indices. generally, with increasing $\mu$, the optimum frequency ratio decreases or stays fixed (in some parts) in all three indices. 
3) optimum damping ratios for all three indices are in range of 0 to $0.18\left(0<\xi_{p}<0.18\right)$ and increase with increasing $\mu$ (except the ending part of the curve related to roof displacement index).

4) in practice, after selecting $\mu$ from desirable range previously recommended in this paper, the optimum frequency and damping ratio $\left(f_{r}^{o p t}, \xi_{p}^{o p t}\right)$ corresponding the selected mass ratio can be taken from the diagrams in figures 9 and 10. then, absolute values of the optimum pendulum's stiffness and optimum pendulum's damping coefficient $\left(k_{p}^{o p t}, C_{p}^{o p t}\right)$ can be calculated from following equations:

$$
\begin{aligned}
& k_{p}^{o p t}=m_{p} \times\left(\omega_{p}^{o p t}\right)^{2} \\
& C_{p}^{o p t}=2 m_{p} \times \omega_{p}^{o p t} \times \xi_{p}^{o p t}
\end{aligned}
$$

In equations (5) and (6), $m_{p}$ and $\omega_{p}^{o p t}$ are derived from selected mass ratio ( $\mu$ ) and its corresponding optimum frequency ratio $\left(f_{r}^{\text {opt }}\right)$, respectively.

\section{References}

1. J. J. Connor, (2002), 'Introduction to Structural Motion Control, First Edition,', Chapter 4 Page 259 Prentice Hall New Jersey.

2. J. Ormondroyd, J. P. Den Hartog, (1928), "The theory of the dynamic vibration absorber," Transactions of the ASME 49 - 50 9-22.

3. R.E.D. Bishop, D. B. Welbourn, (1952), "The problem of the dynamic vibration absorber," Engineering, London 174-769.

4. C.M. Harris, Ch. E. Crede, (1961), 'Shock and Vibration Handbook," The McGraw-Hill Companies Inc., USA.

5. S. Kaliski, et al., (1966), "Vibration and Waves in a Solid Body (in Polish)," PWN, Warsaw.

6. Shum KM, Xu YL, (2004), 'Multiple tuned liquid column dampers for reducing coupled lateral and torsional vibration of structures,' 'Eng Struct 26 745-58.

7. Zuo Lei, Nayfeh Samir A, (2005), 'Optimization of the individual stiffness and damping parameters in multiple-tuned-mass-damper systems,' J Vib Acoust 127 77-83.

8. Guo YQ, Chen WQ, (2007), 'Dynamic analysis of space structures with multiple tuned mass dampers,' Eng Struct 29 3390-403. 
9. J.D. Holmes, (1995), "Auxiliary damping systems for mitigation of wind-induced vibration," Engineering Structures 179608.

10. Sacks MP, Swallow JC, (1993), "Tuned mass dampers for towers and buildings," Proceedings of the Symposium on Structural Engineering in Natural Hazards Mitigation, Irvine, CA 640-645.

11. Kwok KCS, Samali B, (1995), "Performance of tuned mass dampers under wind loads,' Engineering Structures 17 655-667.

12. Fischer O, (2007), "Wind-excited vibrations - solution by passive dynamic vibration absorbers of different types,' J Wind Eng Ind Aerodyn 95 1028-39.

13. Sarkar A, Gudmestad OT, (2013), 'Pendulum type liquid column damper (PLCD) for controlling vibrations of a structure - theoretical and experimental study,' Eng Struct 49 221-33. 14. C.W. Roeder, S.P. Schneider, J.E. Carpenter, (1993), "Seismic Behavior of MomentResisting Steel Frames" J. Struct. Eng 119 1866-1884.

15. Anil k. Chopra, (1995), "Dynamics of Structures, Third Edition” Prentice Hall, New Jersey. 